\title{
Using $\beta$-Lactamase to Trigger Supramolecular Hydrogelation
}

\author{
Zhimou Yang, Pak-Leung Ho, Gaolin Liang, Kin Hung .Chow, Qigang Wang, Yang \\ Cao, Zhihong Guo, Bing Xu
}

\section{Supporting Information}

\section{Materials and general methods:}

Chemicals: 7-Amino-3-chloromethyl 3-cephem-4-carboxylic acid diphenylmethyl ester hydrochloride (ACLH) was a gift from Otsuka Chemical Co. Ltd. $\beta$-lactamase was obtained from Fluka chemicals (15-25 U/mg, $1 \mathrm{U}$ corresponds to the amount of enzyme which hydrolyzes $1 \mu \mathrm{mol}$ of Cephalosporin $\mathrm{C}$ per minute at pH 7.0 and $25^{\circ} \mathrm{C}$ ). All the other starting materials were obtained from Aldrich or Sigma. Commercially available reagents were used without further purification, unless noted otherwise. The solvents were dried according to regular protocols. All other chemicals were reagent grade or better.

General methods: The synthesized compounds were characterized using ${ }^{1} \mathrm{H}$ NMR (Bruker ARX 300) using $\mathrm{CDCl}_{3}$ or DMSO- $\mathrm{d}_{6}$ as the solvent. MALDI-MS spectrometric analyses were performed at the Finnigan TSQ7000 System, circular dichroism spectra on a JASCO J-810 spectropolarimeter, emission spectra on a Perkin-Elmer LS-55 luminance spectrometer, HPLC analysis on Waters 600E Multi-solvent Delivery System using XTerra MS $\mathrm{C}_{18} \mathrm{RP}$ column with $\mathrm{CH}_{3} \mathrm{CN}(0.1 \%$ of TFA) and water ( $0.1 \%$ of TFA) as the eluent, and transmission electron micrograph (TEM) on a JEOL 2010 transmission electron microscope, operating at $200 \mathrm{kV}$. Rheology test was performed on Rheometrics ARES with a cone and plate ( $50 \mathrm{~mm}$ diameter plate and $0.0483 \mathrm{rad}$ cone angle), the gap opening at the apex of the cone and plate was set to $0.0457 \mathrm{~mm}$. The cryo-dried samples were prepared as following: a copper grid coated with carbon was dipped into the hydrogel and placed into a vial, which was plunged into liquid nitrogen. Then, water was removed from the frozen specimen by a freeze-drier.

\section{Syntheses and characterizations:}

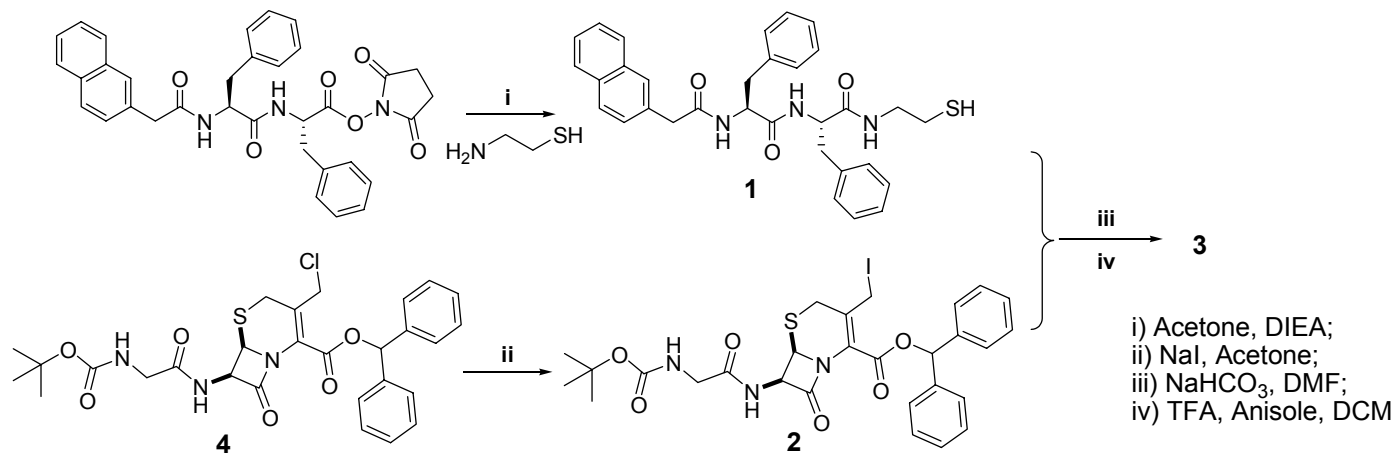

Scheme S1

Compound $\mathbf{3}$ was synthesized according to Scheme S1, and the preparations of compound $\mathbf{2}$ and $\mathbf{3}$ were followed the literature methods[1]. 
Preparation of Nap-FFE-SH (1): 2-aminoethanethiol (154 mg, $2 \mathrm{mmol}$ ), diisopropylethylamine (DIPEA) (645 mg, $5 \mathrm{mmol}$ ) and the N-hydroxysucinimide (NHS) activated Nap-FF (577 mg, $1 \mathrm{mmol}$ ) were dissolved in $50 \mathrm{~mL}$ of acetone. The resulting solution was stirred at room temperature for 10 hours. After the removal of the solvent on a rotary evaporator, $20 \mathrm{ml}$ of hexane was used to wash the crude product. The residue was purified by flash chromatography on silica gel (eluent: $\mathrm{CHCl}_{3} / \mathrm{MeOH}=$ 9/1) to afford $465 \mathrm{mg}$ of compound 1 (86.3\%). ${ }^{1} \mathrm{H}$ NMR (300 MHz, DMSO-d $\left.\mathrm{d}_{6}\right): \delta 8.45-8.48(\mathrm{~d}, 1 \mathrm{H})$, 8.37-8.40 (d, 1H), $8.29(\mathrm{~s}, 1 \mathrm{H}), 8.00-8.03(\mathrm{~d}, 1 \mathrm{H}), 7.89-7.95(\mathrm{t}, 2 \mathrm{H}), 7.76(\mathrm{~s}, 1 \mathrm{H}), 7.61-7.64(\mathrm{~m}, 2 \mathrm{H})$, 7.30-7.40 (m, 11H), 4.63-4.70 (m, 2H), 3.63-3.77 (q, 2H), 3.40-3.49 (m, 2H), 3.10-3.16 (m, 2H), 2.76-3.02 (m, 4H). MS: calc. $\mathrm{M}^{+}=539.22$, obsvd. $(\mathrm{M}+1)^{+}=540.23$.

Preparation of protected Nap-FFE-ACLH (3): A mixture of 4 (0.286 g, $0.5 \mathrm{mmol})$ and sodium iodide $(0.403 \mathrm{~g}, 5.0 \mathrm{mmol})$ in $6 \mathrm{~mL}$ of acetone was stirred for $1 \mathrm{hr}$ at ambient temperature. The reaction mixture was concentrated under reduced pressure and diluted with $5 \mathrm{~mL}$ of water. The suspension was extracted with $25 \mathrm{~mL}$ of ethyl acetate, and the organic phase was washed with $10 \%$ sodium thiosulfate $(5 \mathrm{~mL})$, water $(5 \mathrm{~mL})$, brine $(5 \mathrm{~mL})$ and dried over anhydrous magnesium sulfate. The slightly orange powder was used without purification. The iodo derivative was dissolved in $0.4 \mathrm{~mL}$ of DMF and followed by $38.6 \mathrm{mg}$ of sodium bicarbonate. Then $270 \mathrm{mg}(0.50 \mathrm{mmol})$ of 1 in $5.0 \mathrm{~mL}$ of DMF was added. The mixture was stirred under room temperature overnight. After that, the reaction mixture was diluted by water $(20 \mathrm{~mL})$ and extracted by ethyl acetate $(100 \mathrm{~mL})$. The organic phase was washed by brine $(10 \mathrm{~mL})$ and water $(10 \mathrm{~mL})$ and dried over anhydrous sodium sulfate. The solvent was removed and residue was purified by flash chromatography on silica gel (eluent: $\mathrm{CHCl}_{3} /$ hexane $=3: 2$ ) to afford $281 \mathrm{mg}$ of desired product (52.3\%). ${ }^{1} \mathrm{H}$ NMR (300 MHz, DMSO-d $\left.)_{6}\right) \delta 8.98-9.01(\mathrm{~d}, 1 \mathrm{H}), 8.40-8.44(\mathrm{~d}$, $1 \mathrm{H}), 8.34-8.39(\mathrm{~d}, 1 \mathrm{H}), 8.19(\mathrm{t}, 1 \mathrm{H}), 8.00-8.03(\mathrm{~d}, 1 \mathrm{H}), 7.89-7.98(\mathrm{~m}, 2 \mathrm{H}), 7.57-7.67(\mathrm{~m}, 6 \mathrm{H})$, 7.43-7.54 (m, 7H), 7.32-7.37 (m, 11H), 7.13-7.18 (t, 1H), $7.09(\mathrm{~s}, 1 \mathrm{H})$, 5.90-5.93 (m, 1H), 5.35-5.36 (d, $1 \mathrm{H}), 4.62-4.70(\mathrm{~m}, 2 \mathrm{H}), 3.63-3.85(\mathrm{~m}, 8 \mathrm{H}), 3.30-3.36(\mathrm{~m}, 2 \mathrm{H}), 3.09-3.15(\mathrm{~m}, 3 \mathrm{H}), 2.89-3.00(\mathrm{~m}, 2 \mathrm{H})$, 2.52-2.56 (t, 2H). MS: calc. $\mathrm{M}^{+}=1074.40$, obsvd. $(\mathrm{M}+1)^{+}=1075.42$.

Preparation of Nap-FFE-ACLH (3): To a solution of protected $3(269 \mathrm{mg}, 0.25 \mathrm{mmol})$ in $10 \mathrm{~mL}$ of anhydrous dichloromethane was added anisole $(0.5 \mathrm{~mL})$ and trifluoroacetic acid $(1.5 \mathrm{~mL})$ with cooling (ice bath). The mixture was stirred for $2 \mathrm{hr}$ at the same temperature. After the removal of the solvent on rotary evaporator, $50 \mathrm{~mL}$ of ether was used to wash the crude product. The precipitate was collected and washed with ether $(10 \mathrm{~mL} \times 3)$ to afford $192 \mathrm{mg}(95.0 \%)$ of yellow product. The yellow product was further purified by HPLC. ${ }^{1} \mathrm{H}$ NMR $\left(300 \mathrm{MHz}, \mathrm{DMSO}-\mathrm{d}_{6}\right) \delta 9.48-9.50(\mathrm{~d}, 1 \mathrm{H}), 8.43-8.45(\mathrm{~d}, 1 \mathrm{H})$, 8.33-8.35 (d, 1H), 8.15-8.30 (m, 3H), 8.00-8.03 (d, 1H), 7.89-7.97 (m, 2H), $7.76(\mathrm{~s}, 1 \mathrm{H}), 7.61-7.65(\mathrm{~m}$, 2H), 7.41-7.46 (m, 1H), 7.30-7.40 (m, 8H), 7.25-7.27 (d, 1H), 7.15-7.19 (d, 1H), 7.04-7.06 (d, 1H), 5.90-5.93 (m, 1H), 5.33-5.35 (d, 1H), 4.65-4.70 (m, 2H), 3.63-3.90 (peaks in the water peak), 8H), 3.25-3.50 (m, 3H), 3.06-3.18 (m, 2H), 2.89-3.00 (m, 2H). MS: calc. $\mathrm{M}^{+}=808.27$, obsvd. $(\mathrm{M}+1)^{+}=$ 809.28 . 


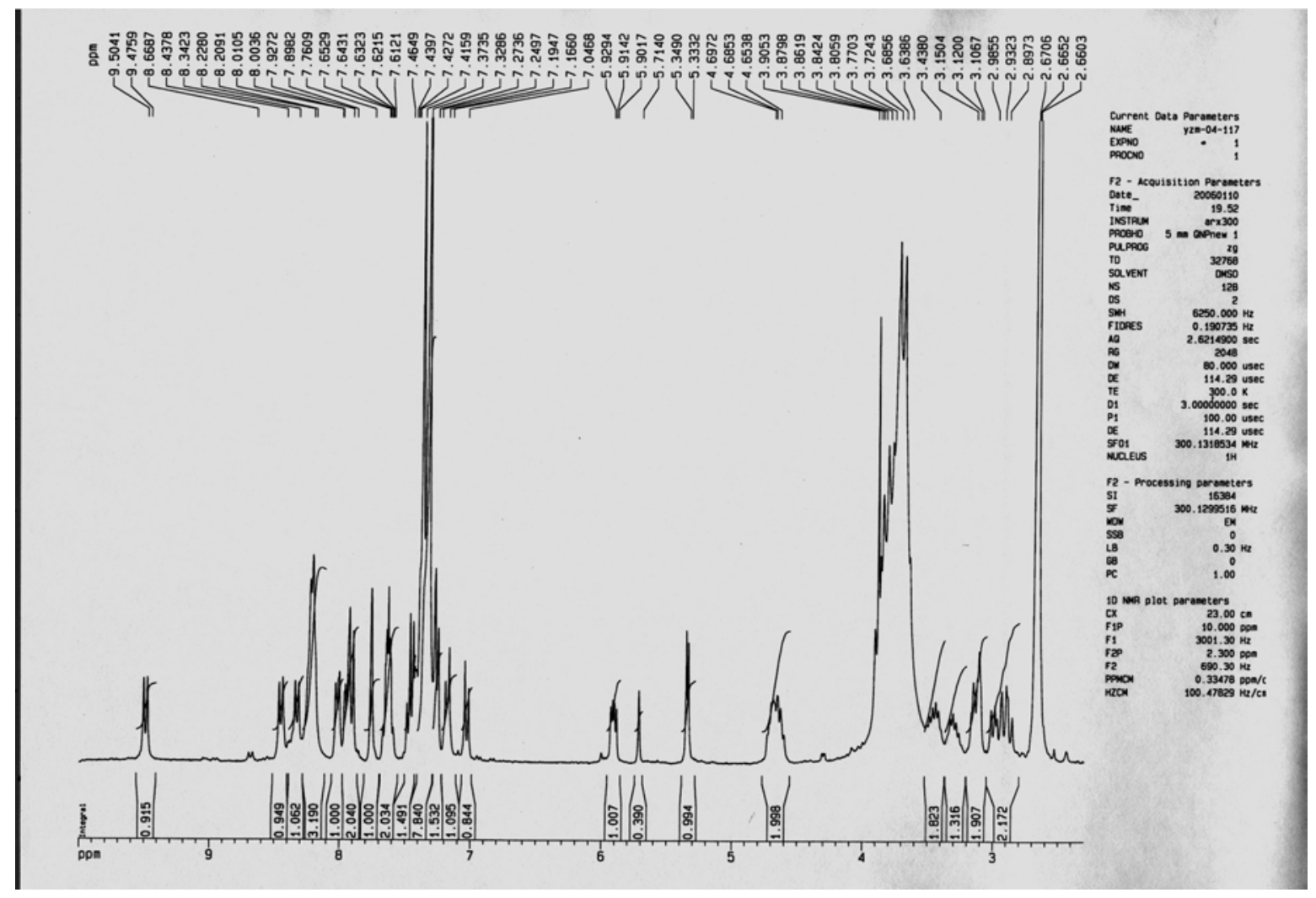

Figure $\boldsymbol{S}$-1. The NMR spectrum of compound 3.

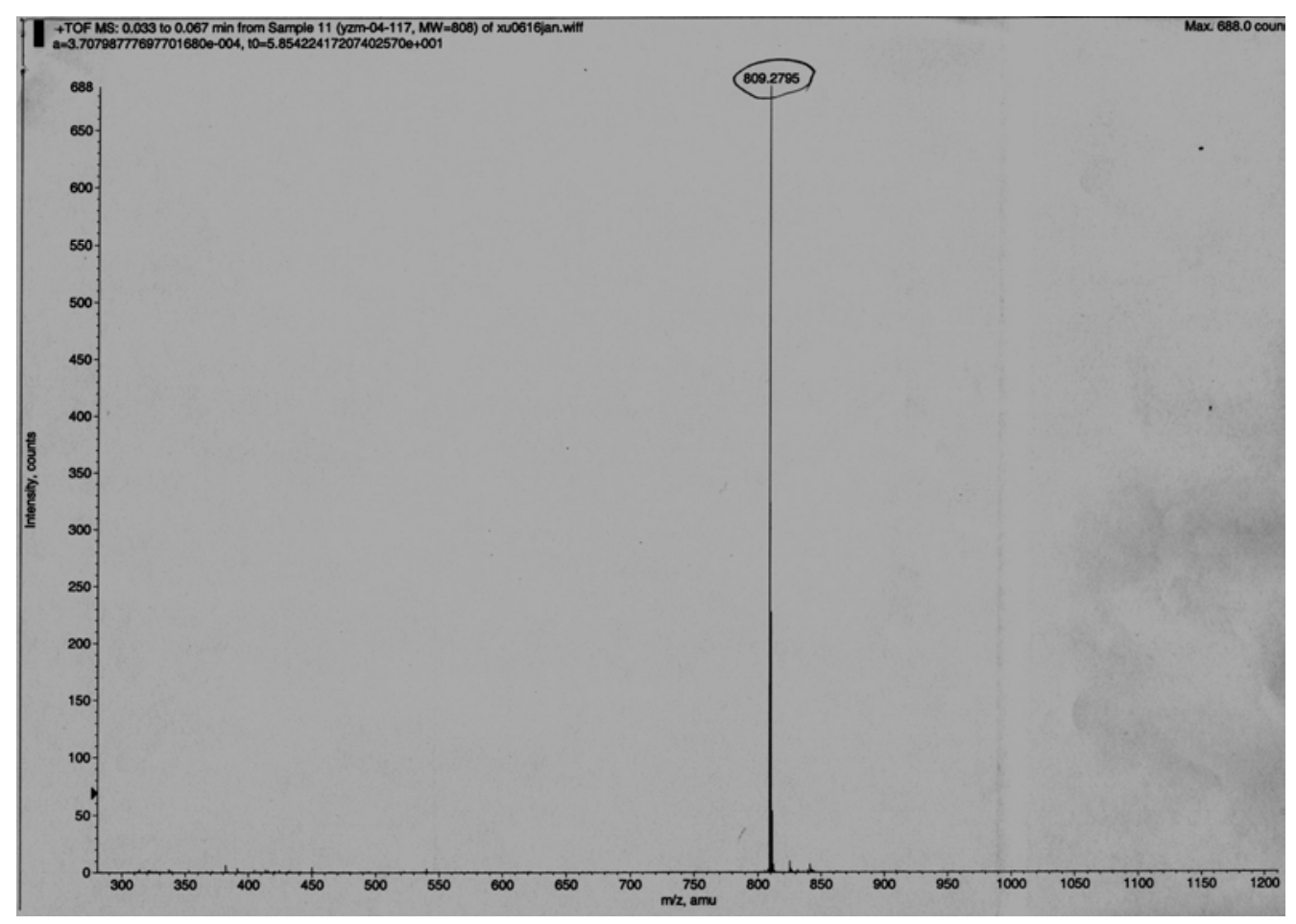

Figure S-2. The mass spectrum of compound 3. 


\section{Schematic illustration for enzymatic formation of supramolecular hydrogel (scheme S2):}
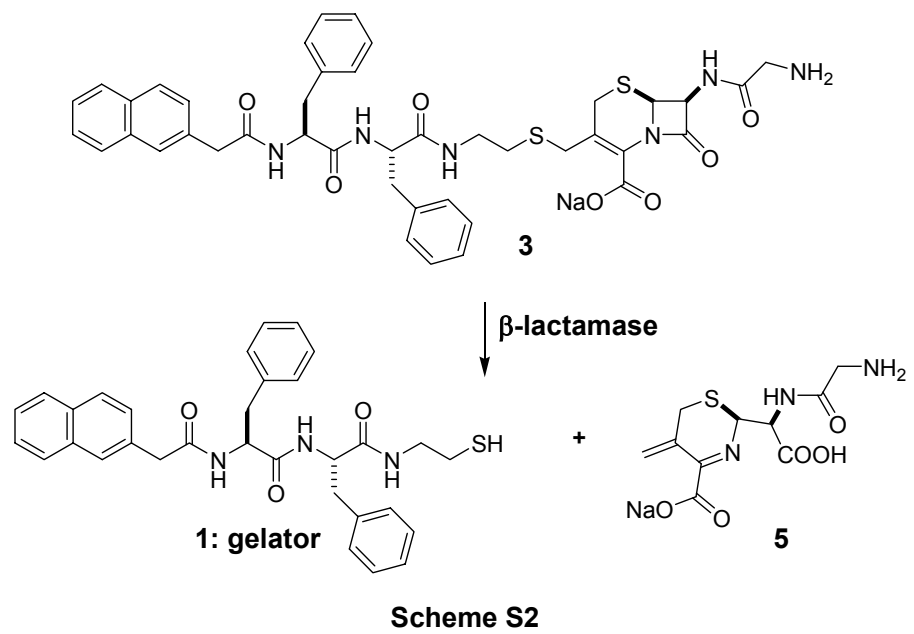

Formation of gel I. $1.75 \mathrm{mg}(2.17 \mu \mathrm{mol})$ of compound $\mathbf{3}$ was dissolved in $0.50 \mathrm{~mL}$ of water $(\mathrm{pH}=8.0)$. To the above viscous liquid, $0.55 \mathrm{mg}$ of $\beta$-lactamase was added. The transparent gel (gel I) formed after the solution was keeping at room temperature for about half an hour.

Rheology experiment. $1.2 \mathrm{~mL}$ of the gel I was sandwiched between the cone plates to obtain the strain curve at the frequency of $1.0 \mathrm{rad} / \mathrm{s} .1 .2 \mathrm{~mL}$ of the gel I was sandwiched between the cone plates to obtain the frequency curve at the strain of $0.3 \%$. The solution containing $4.2 \mathrm{mg}$ of $\mathbf{3}$ and $1.32 \mathrm{mg}$ of $\beta$-lactamase in $1.2 \mathrm{~mL}$ water $(\mathrm{pH}=8.0)$ was sandwiched between the cone plate at the strain of $0.3 \%$ and the frequency of $1.0 \mathrm{rad} / \mathrm{s}$ for dynamic time sweep experiment. All rheological measurements are carried out at room temperature $\left(25-26^{\circ} \mathrm{C}\right)$.
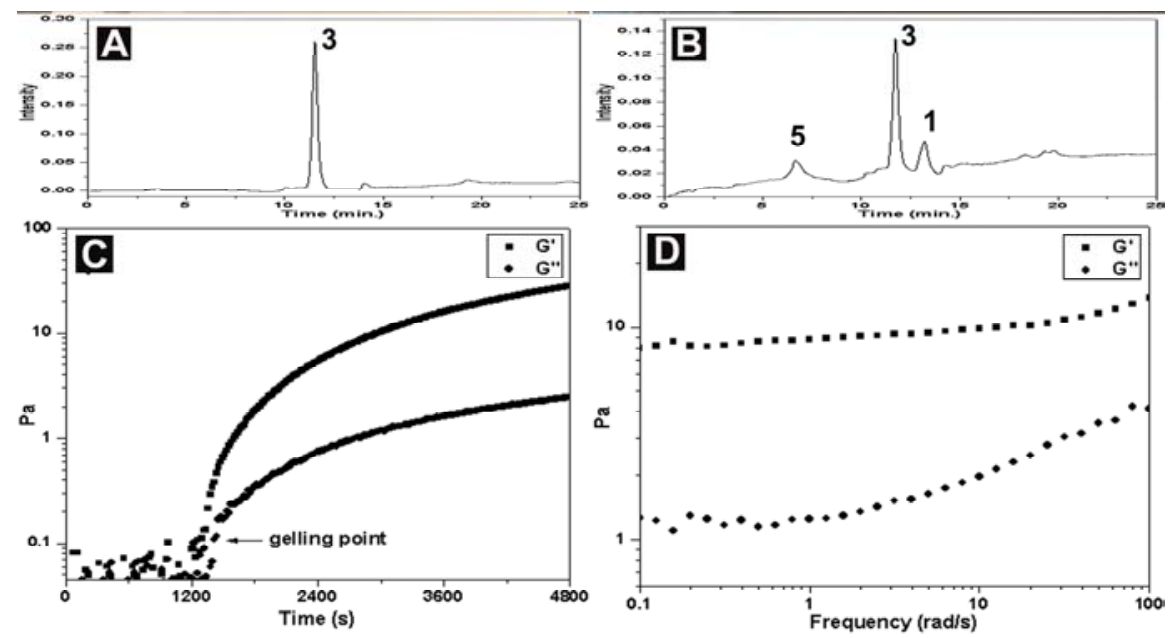

Figure S-3. HPLC traces of (A) viscous solution of $\mathbf{3}$ and B) gel I. (C) Dynamic time sweep of a solution containing $0.35 \mathrm{wt} \%$ of $3,0.11 \mathrm{wt} \%$ of $\beta$-lactamase. $\mathrm{pH}=8.0$ (the arrow indicates the formation of the gel). (D) Dynamic frequency dependence of the storage modulus (G') and the loss modulus (G”) of gel I. 
Table S-1. Eluting gradient for HPLC analysis of all hydrogels and solutions of $\mathbf{3}$.

\begin{tabular}{|c|c|c|c|}
\hline Time (minute) & Flow (mL/min.) & $\mathrm{H}_{2} \mathrm{O} \%$ & $\mathrm{CH}_{3} \mathrm{CN} \%$ \\
\hline 0 & 5.0 & 70 & 30 \\
\hline 13 & 5.0 & 10 & 90 \\
\hline 20 & 5.0 & 10 & 90 \\
\hline 21 & 5.0 & 70 & 30 \\
\hline 25 & 5.0 & 70 & 30 \\
\hline
\end{tabular}

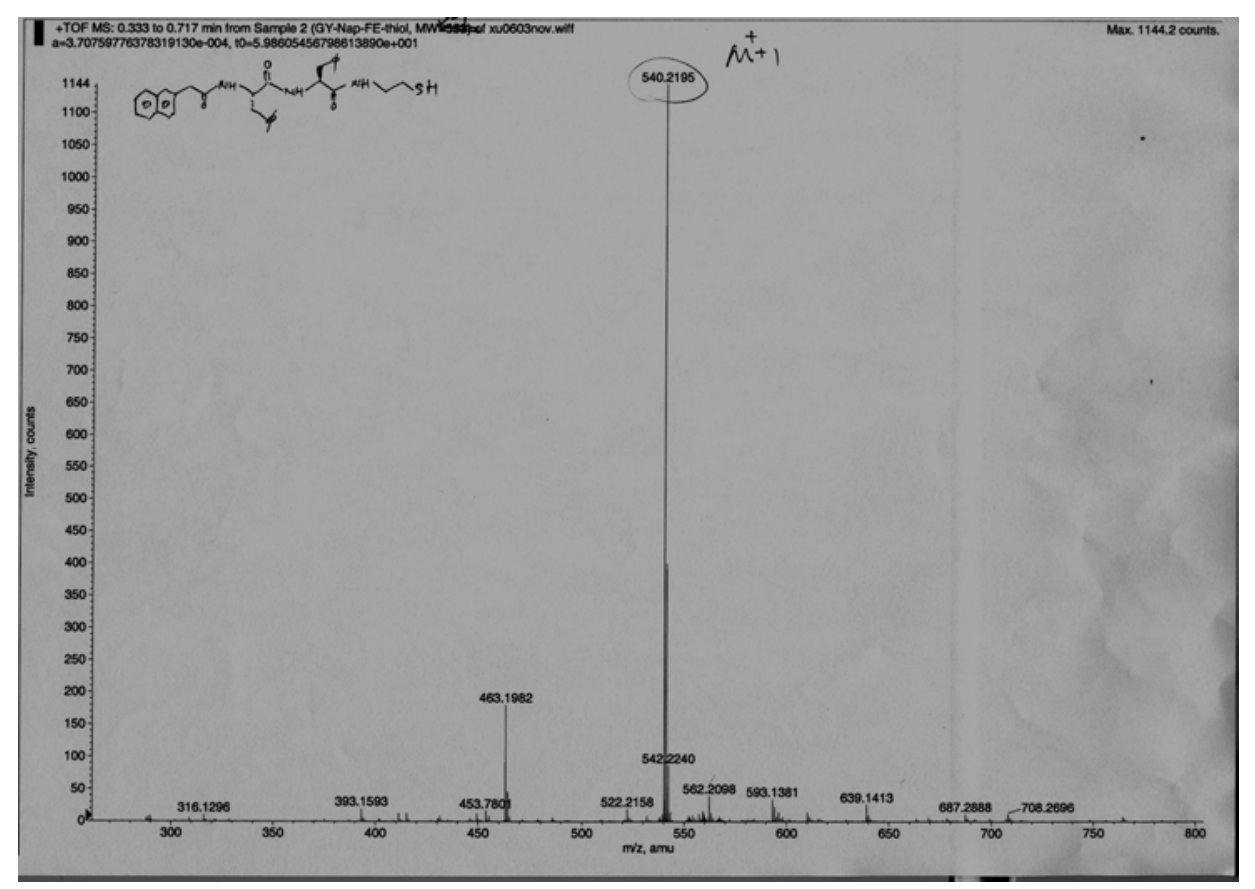

Figure $\mathbf{S}$-4. The mass spectrum of compound 1.

\section{The general protocol for preparing cell lysates is described as following:}

1. The bacteria are cultured on nutrient agar at $37^{\circ} \mathrm{C}$ overnight.

2. Using $10 \mu \mathrm{L}$ sterile disposable loops, transfer and emulsify the bacteria to $1 \mathrm{ml}$ milli-Q water in $1.5 \mathrm{ml}$ sterile microcentrifuge tube.

3. The suspension is frozen at $-70^{\circ} \mathrm{C}$ for 10 minutes.

4. The suspension is then thawed at room temperature for 30 minutes.

5. Repeat steps 3 and 4 three times.

6. Sonicate the suspension at $4^{\circ} \mathrm{C}$ for 3 minutes.

7. The crude enzyme extraction is centrifuged at $13200 \mathrm{rpm}$ for 15 minutes at $4^{\circ} \mathrm{C}$.

8. Supernatant is collected by passing through $0.22 \mu \mathrm{m}$ membrane filter to a new $1.5 \mathrm{ml}$ sterile microcentrifuge tube.

9. Sterility check of the enzyme extraction is performed to guarantee no viable organism left.

10. Activity of enzyme is checked with nitrocephin-based $\beta$-lactamase test. 
11. The enzyme extract is stored in $-70^{\circ} \mathrm{C}$ before use.

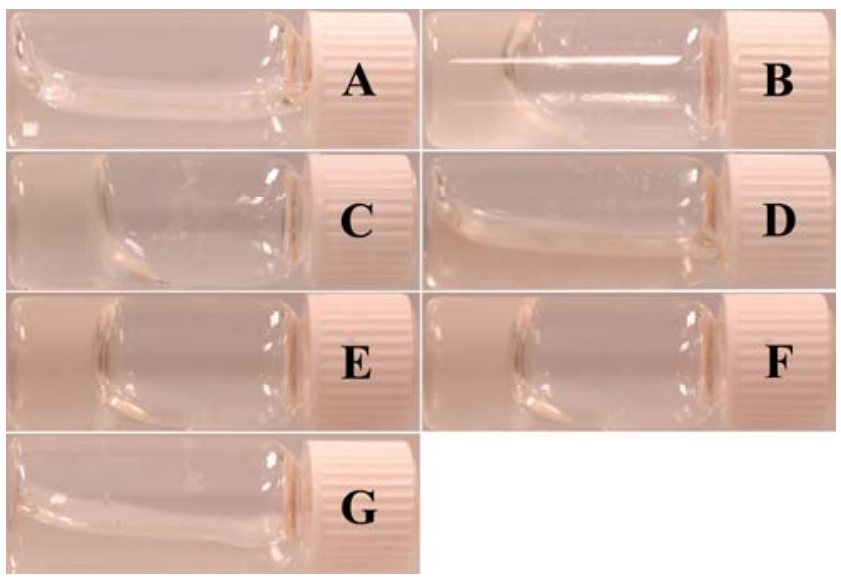

Figure $\boldsymbol{S - 5}$. The results of adding different types of cell lysates $(0.1 \mathrm{~mL}$ ) into $0.4 \mathrm{~mL}$ of solution of $\mathbf{3}$ (in the end Conc. of 3 is $0.35 \mathrm{wt} \%, \mathrm{pH}=8.0$ ): A) E Coli with C600, B) E Coli with CTX-M13, C) E Coli with CTX-M14, D) E Coli with JP995, E) E Coli with SHV-1, F) E Coli with TEM-1, and G) water.
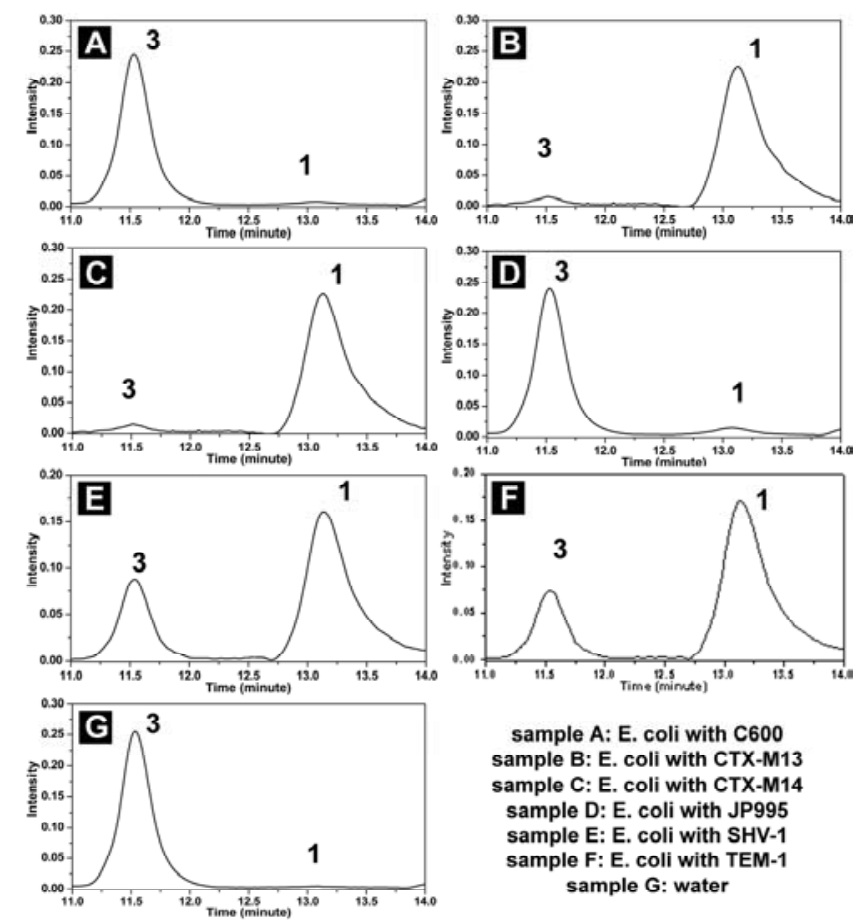

Figure S-6. HPLC traces of A) gel in Figure S-4A, B) solution in Figure S-4B, C) gel in Figure S-4C, D) solution in Figure S-4D, E) solution in Figure S-4E, F) solution in Figure S-4F, and G) solution in Figure S-4G. 
Table S-2. Samples used to test hydrogelations.

\begin{tabular}{|c|c|c|c|c|c|c|}
\hline Sample & $\begin{array}{c}\text { Enzyme in the } \\
\text { extract }\end{array}$ & Strain name & $\begin{array}{l}\text { Time to change } \\
\text { nitrocefin color }\end{array}$ & $\begin{array}{c}\text { Bacterial density } \\
(\mathrm{CFU} / \mathrm{mL}) \text { used to } \\
\text { prepare enzyme extract }\end{array}$ & $\begin{array}{c}\text { Beta-lactamase } \\
\text { activity }\end{array}$ & ESBL \\
\hline A & c600 (EC59) & EC59 & $\begin{array}{l}\text { Slight colour change } \\
\text { after } 10 \text { mins }\end{array}$ & $3.30 \mathrm{E}+10$ & negative & \\
\hline B & CTX-M13 & J3701X1 & $3 \mathrm{sec}$ & $4.40 \mathrm{E}+10$ & positive & yes \\
\hline $\mathrm{C}$ & $\begin{array}{c}\text { CTX-M14 } \\
\text { (transconjugate) }\end{array}$ & 53T2X-Combat2D1 & $5 \mathrm{sec}$ & $4.80 \mathrm{E}+10$ & positive & yes \\
\hline $\mathrm{D}$ & JP995 & JP995 & $3 \mathrm{~min}$ & $4.40 \mathrm{E}+10$ & negative & \\
\hline $\mathrm{E}$ & SHV-1 & EC35 & $4 \mathrm{~min}$ & $2.70 \mathrm{E}+10$ & positive & no \\
\hline $\mathrm{F}$ & TEM-1 & EC50 & $1 \mathrm{~min}$ & $2.00 \mathrm{E}+10$ & positive & no \\
\hline $\mathrm{G}$ & Water & None & $\infty$ & none & negative & \\
\hline
\end{tabular}

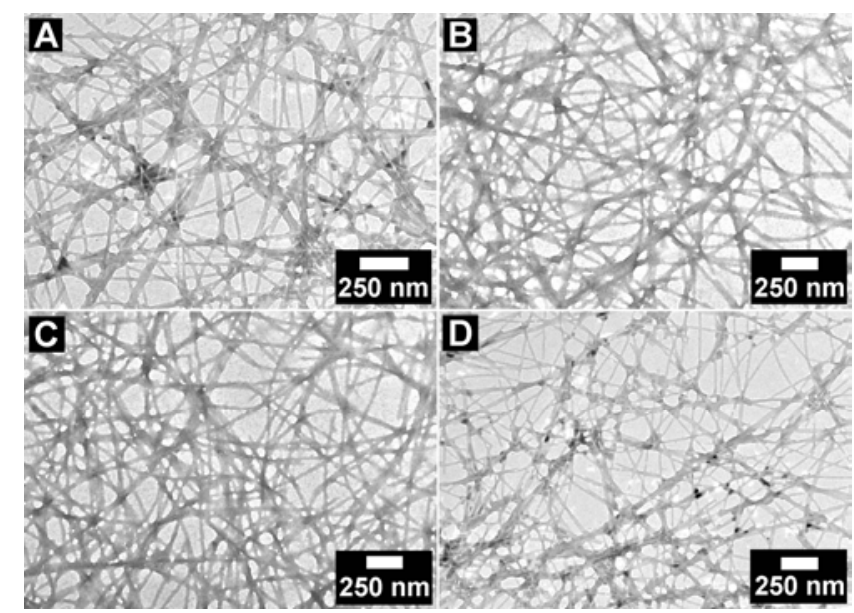

Figure S-7. TEM images of A) gel in Figure S-4B, B) gel in Figure S-4C, C) gel in Figure S-4E, and D) gel in Figure S-4F.

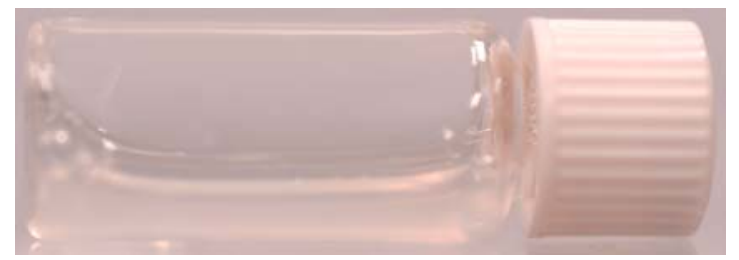

Figure S-8. Optical image of a $0.5 \mathrm{~mL}$ of solution containing $1.75 \mathrm{mg}$ of $3,0.55 \mathrm{mg}$ of beta-lactamase, and 25 $\mu \mathrm{g}$ of clavulanic acid (potassium salt) $(\mathrm{pH}=8.0)$ (the enzyme solution is firstly incubated with clavulanic acid for 10 minutes) after 12 hours. 


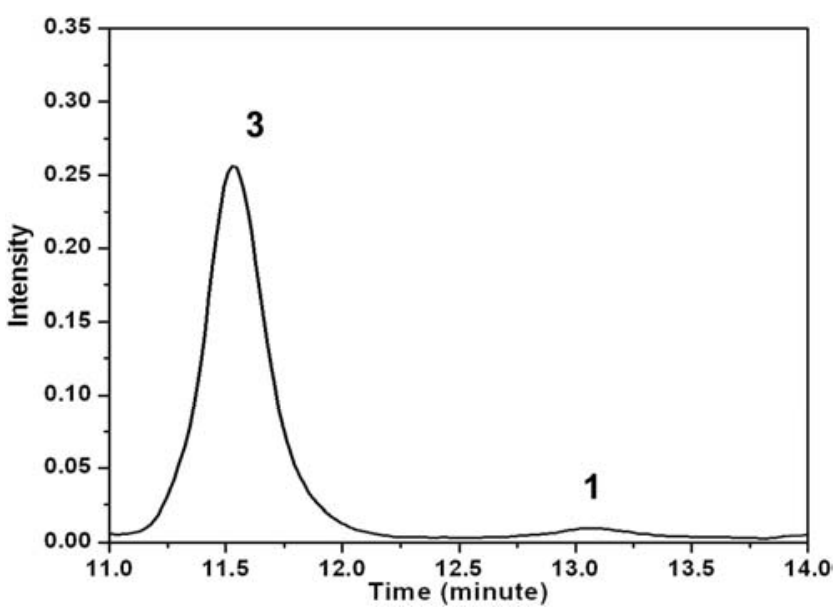

Figure S-8. HPLC trace of the solution in Figure S-7.

[1] Xing, B.; Khanamiryan, A.; Rao, J. H. J. Am. Chem. Soc. 2005, 127, 4158-4159. 